\title{
OCCURRENCE OF CRYPTOSPORIDIUM OOCYSTS AND HELMINTH OVA ON DRIED CRAYFISH (PROCAMBARUS CLARKII) SOLD IN KADUNA STATE, NIGERIA
}

\author{
Esonu, D. O., Kia, G. S. N., Evelyn, O., Mathias, S. \\ Department of Veterinary Public Health and Preventive Medicine \\ Faculty of Veterinary Medicine \\ Ahmadu Bello University Zaria, Kaduna State \\ Nigeria \\ esonu25@gmail.com
}

\section{ABSTRACT}

Cryptosporidium spp. and helminths are responsible for diarrhoal illness in humans and many other animals. The transmission routes of these parasites suggest a risk for human infection through contaminated foods. In order to determine the occurrence of Cryptosporidium oocysts and helminth ova on dried crayfish (Procambarus clarkii) sold in Zaria and Kaduna Central market, Kaduna State, 100 crayfish samples were examined using the modified Ziehl-Neelsen staining technique for Cryptosporidium oocyst and the flotation technique for helminth ova. The measurements of the oocysts from the positive samples were estimated by using a calibrated microscope eyepiece. The prevalence of Cryptosporidium oocysts in dried crayfish was $20.0 \%$ while the location-based prevalence was $43.3 \%, 5.0 \%$, and $12.0 \%$ for Sabo, Samaru and Kaduna central market, respectively. Micrometry revealed that the oocysts size ranged from $3.68 \mu \mathrm{m}$ to $4.7 \mu \mathrm{m}$. Also, the prevalence of helminth ova in dried crayfish was $19 \%$, while the spe- cific prevalence based on location showed a higher prevalence in Sabo (30.0 \%) than in Kaduna central market (18.0 \%) and Samaru (5.0\%). The helminth eggs recovered from this study included: Toxocara spp. (4.0\%), Ascaris spp. (7.0\%), Trichuris spp. (4.0\%), Schistosoma spp. (2.0\%), Ancylostoma spp. (1.0\%), and Capillaria spp. $(1.0 \%)$. The analysis of the questionnaires revealed that $71(71.0 \%)$ of the respondents ate uncooked crayfish and $44.0 \%$ used their bare hands to handle the crayfish. There was no statistically significant association $(\mathrm{P}>0.05)$ between the prevalence of Cryptosporidium oocysts or helminth ova and the locations sampled. This study has shown that dried crayfish obtained from markets within the study area were contaminated with parasite ova and oocysts, thus public enlightenment on the dangers of the consumption of raw or undercooked dried crayfish should be well publicized.

Key words: crayfish; Cryptosporidium; helminth ova; oocysts; Ziehl-Neelsen 


\section{INTRODUCTION}

Cryptosporidium is an intracellular protozoan parasite that causes gastrointestinal pathologies in all vertebrates such as mammals, reptiles, birds and fish; thus, it is one of the most predominant enteric parasitic pathogens in humans [23]. Cryptosporidium is an important cause of diarrhoeal diseases alongside of Giardia in humans globally and is included in the WHO neglected disease initiatives [20]. The organism affects the epithelial cells of both the digestive and respiratory tracts and multiplies in them [6]. Cryptosporidium is also a relevant food borne pathogen resulting in diseases of socioeconomic importance globally [17].

Cryptosporidiosis is ubiquitous in its infectivity, and has an undesirable worldwide reputation [4]. The growing concern of cryptosporidiosis affecting immunocompromised individuals has led to the introduction of control measures of the disease in humans and other animals; which is of public health significance [9]. Humans are susceptible to infection by Cryptosporidium via many transmission pathways. Infection occurs through the consumption of contaminated food or physical contact with faeces of infected individuals [8]

Helminthosis is also of great concern because scientists have discovered that rivers are infected with numerous helminths [1]. There is a high health risk associated with helminth infections because helminths persist for longer periods in the environment, its host immunity is usually low to non-existent and the infective dose is small. Helminth infections are estimated to be the cause of 135,000 deaths annually around the globe [11].

Crayfish are crustaceans resembling tiny lobsters. They are colloquially called crawfish or crawdads. Taxonomically, they are members of the superfamilies Astacoidea and Parastacoidea. Some species of crayfish are found in brooks and streams where freshwater is running, while others thrive in swamps, ditches and paddy fields [16]. P. clarkii has been eaten in the United States, Cambodia, Europe, China, Africa, Australia, Thailand, Canada, New Zealand, and the Caribbean [13]. This species is typically dark red, with long claws and head, small or no spines on the sides of its carapace just below the head, and rows of bright red bumps on the front and side of the first leg [15].

Several "external" nematodes have been reported on crayfish, and these can be considered to be free-living epibionts with limited impact on host survival $[7,10]$. Truly parasitic nematodes are normally found within crayfish internally, either encysted in the muscles or encapsulated on the intestinal wall; few parasitic nematodes such as Gnathostoma spinigerum, Angiostrongylus cantonensis have been reported in crayfish, with crayfish acting as paratenic hosts in all cases [14]. T a y lor et al. [21] also identified crayfish as the intermediate host for Paragonimus westermani and Polymorphus boschadis. Furthermore, $\mathrm{A} \mathrm{b} \mathrm{r} \mathrm{a} \mathrm{h} \mathrm{a} \mathrm{m} \mathrm{et} \mathrm{al.} \mathrm{[1]} \mathrm{detected} \mathrm{Porospora} \mathrm{gigantica}$ (sporozoa), Nicothoic astaci (copepod), Hysterothylaactum spp. (nematode), Paragonimus uterobilateralis (trematode), Leech-like parasite (hirudinea) and Polymorphus botulus (acanthocephalan) on crayfish and lobsters in Great Kwa river of Cross river State, Nigeria. Reports presented at the Infectious Disease Society of America's (IDSA's) annual conference revealed that contaminated crayfish can cause severe illnesses such as salmonellosis and Vibrio mimicus infections [16].

Cryptosporidiosis and helminthosis affect humans and other animals; hence their public health significance. The literature on parasitic zoonoses of crayfish in Kaduna State was unavailable at the time this research was done. Therefore, there was a need for research in this field. Research in parasitic zoonoses of crayfish is important since crayfish is a common seasoning/condiment added to soup and food in general. This study may reveal possible risk factors associated with contamination of crayfish sold at the market. The aim of this study was to determine the occurrence of Cryptosporidium oocysts and helminth ova and also the knowledge and practices of dried crayfish sellers in relation to its handling and sales in Zaria and Kaduna Central market, Kaduna State, Nigeria.

\section{MATERIALS AND METHODS}

\section{Study design}

This was a cross-sectional study in which three markets within Kaduna State were selected, i.e. Sabo (30), Samaru (20) and Kaduna central markets (50), which gave a total sample size of 100 . The sampling was achieved using the simple random sampling method from consenting sellers from June to July, 2017. 


\section{Questionnaire administration}

By using oral interviews, questionnaires (100) were administered to the crayfish sellers within the selected markets to determine the relationship between knowledge and practices of dried crayfish sellers in relation to their handling and sales within the study areas.

\section{Sample collection}

Smoked dried crayfish were bought randomly from the sellers who consented to the questionnaire. Each sample was packaged in small polythene bags, labelled with a number and then transported to the Parasitic Zoonosis Laboratory, Department of Veterinary Public Health and Preventive Medicine, Faculty of Veterinary Medicine, Ahmadu Bello University, Zaria.

\section{SAMPLE PROCESSING}

\section{Preparation of homogenate}

Ten grams of each sample of the crayfish was weighed on a measuring scale. It was then put in a sterile polythene bag and $90 \mathrm{ml}$ of peptone water was added. The contents were tied up in the polythene bag and put in a stomacher for homogenization. The homogenate was then centrifuged and the supernatant was decanted. Part of the sediment was used as a flotation technique to detect the helminth ova. The other portion of the sediment was used to make a thin smear on glass slides in order to stain for Cryptosporidium oocysts, using a modified Ziehl-Neelsen staining technique as described by $\mathrm{Ch}$ e e s b r o u g h [5].

\section{The detection of the Cryptosporidium oocysts used the modified Ziehl-Neelsen staining method}

Briefly, the slides were fixed with ethanol for $2-3 \mathrm{~min}$ utes, then stained with carbol-fuschin for 15 minutes and washed with water. The slides were then counter-stained with $0.3 \%$ methylene blue for 30 seconds, then washed with water and allowed to air dry. The stained slides were viewed using the light microscope at 40 objective lens. Cryptosporidium oocysts appeared red on a blue background. The degree and proportion of staining varied between oocysts. The internal structures took up various degree of stain from amorphous to eccentric. Cryptosporidium oocysts appeared as spherical discs with diameters ranging from 2.94 to $9.0 \mu \mathrm{m}$ [21]. The measurements of all oocysts from the positive samples were conducted using a calibrated microscope eyepiece.

\section{Detection of helminth ova}

This was achieved using the flotation technique as described by Arora and Arora [2]. The homogenates of crayfish were filtered using gauze and a funnel into a centrifuge test tube. The filtrate was centrifuged at 2,000 revolutions per minute for 5 minutes, the supernatant was decanted and Zinc sulphate solution was added up to the brim of the test tube until a convex meniscus was formed. Cover-slips were gently placed on top of the flotation medium and allowed to stay for ten minutes. After some time, the cover-slips were gently taken off and the flotation smear homogenized; the flotation medium was discarded and the sediment at the bottom of the sample bottle was smeared at another corner of the glass slide, thus each slide had two smears: one for flotation and the other for sedimentation. The slides were allowed to air dry for 24 hours at room temperature and then viewed at x10 on the microscope. The eggs were identified on the basis of their morphological features as described by $\mathrm{U} r \mathrm{qu}$ h a $\mathrm{r} \mathrm{t}$ et al. [22].

\section{Data analysis}

Using Graph pad prism version 5, Pearson's correlation (r) and Chi square $\left(\chi^{2}\right)$ were calculated to determine the association between independent and dependent variables. P-values less than or equal to 0.05 were considered statistically significant. The relationship between knowledge and practices of dried crayfish sellers in relation to their handling and sales were determined from the questionnaires administered using SPSS version 21.

\section{RESULTS}

The overall prevalence of Cryptosporidium oocysts in the dried crayfish from the markets within the study area was $20 \%$. Location-based prevalences were $43.3 \%$, $5.0 \%$, and $12.0 \%$ for Sabo, Samaru and the Kaduna central market, respectively. Although the prevalence was higher in Sabo market than Samaru and Kaduna central market, there was no statistically significant association $(\mathrm{P}=0.08)$ between the prevalence of Cryptosporidium oocysts and the location sampled upon analysis (Table 1). Micrometry 
Table 1. Locational distribution of Cryptosporidium oocysts on dried crayfish sold in Sabo, Samaru, and Kaduna Central Market

\begin{tabular}{lccccc}
\hline \multicolumn{1}{c}{ Location } & $\begin{array}{c}\text { Number } \\
\text { examined }\end{array}$ & $\begin{array}{c}\text { Number } \\
\text { positive }\end{array}$ & $\begin{array}{c}\text { Specific rate } \\
{[\%]}\end{array}$ & $\mathbf{X}^{2}$ & P value \\
\hline Sabo & 30 & 13 & 43.3 & 9.766 & 0.08 \\
Samaru & 20 & 1 & 5.0 & & \\
Central market & 50 & 6 & 12.0 & \\
\hline Total & $\mathbf{1 0 0}$ & $\mathbf{2 0}$ & $\mathbf{2 0}$ & \\
\hline
\end{tabular}

Table 2. Locational distribution of ova of helminths detected on dried crayfish sold in Sabo, Samaru and Kaduna Central markets using Floatation Technique

\begin{tabular}{lccccc}
\hline \multicolumn{1}{c}{ Location } & $\begin{array}{c}\text { Number } \\
\text { examined }\end{array}$ & $\begin{array}{c}\text { Number } \\
\text { positive }\end{array}$ & $\begin{array}{c}\text { Specific rate } \\
{[\%]}\end{array}$ & $\mathbf{X}^{2}$ & P value \\
\hline Sabo & 30 & 9 & 30.0 & 4.938 & 0.085 \\
Samaru & 20 & 1 & 5.0 & & \\
Central market & 50 & 9 & 18.0 & \\
\hline Total & $\mathbf{1 0 0}$ & $\mathbf{1 9}$ & $\mathbf{1 9}$ & \\
\hline
\end{tabular}

results revealed that the oocysts sizes ranged from $3.68 \mu \mathrm{m}$ to $4.7 \mu \mathrm{m}$. The helminth eggs recovered from this study included: Toxocara spp. (4.0\%), Ascaris spp. (7.0\%), Trichuris spp. (4.0\%), Schistosoma spp. (2.0\%), Ancylostoma spp. (1.0\%), and Capillaria spp. (1.0\%). The overall prevalence of helminth ova in the dried crayfish from the study was $19 \%$, while the specific prevalence based on the location showed a higher prevalence in Sabo (30.0 \%) than Samaru (5.0 \%) and Kaduna central market (18.0\%). Upon analysis there was no statistically significant association $(\mathrm{P}=0.085)$ between the prevalence of helminth ova and the locations sampled (Table 2).

Evaluation of the respondents on knowledge and practices in the handling and sales of dried crayfish in the markets showed that $52 \%$ were within the age of $20-39$ years, most of the sellers were females (64\%) and $50 \%$ of the respondents have been selling dried crayfish for $6-7$ years. Seventy-one $(71 \%)$ of the respondents eat uncooked crayfish and $44 \%$ use their bare hands to handle crayfish, while only $4 \%$ knew that vomiting could be a symptom associated with consumption of uncooked contaminated dried crayfish (Table 3 ).

The results shown in Table 4 indicated the extent to which the listed variables were responsible or contributing to contraction of helminth infection and cryptosporidiosis. There was a significant association between the source of dried crayfish and the occurrence of helminth ova and Cryptosporidium oocysts on crayfish $(\mathrm{P}=0.031)$.

\section{DISCUSSION}

The occurrence of Cryptosporidium oocysts and helminth ova on smoked dried crayfish sold at the market may have been due to poor handling during harvesting, processing, storage and display which predisposed the commodity to contamination as reported by $\mathrm{K} \mathrm{u} \mathrm{mol} \mathrm{u} \mathrm{-}$ J o h n s o n et al. [12]. Poor handling further exposed the commodity to insect infestation and the growth and proliferation of moulds which in turn reduced the quality of the commodity.

The higher prevalence of Cryptosporidium oocysts and helminth ova on dried crayfish sampled in Sabo than those from Samaru and Kaduna central market may imply poor environmental hygiene. Furthermore, a mechanical vector (houseflies) may have been attracted by the aroma of crayfish and their enormous number in this location could probably be due to the activities of meat sellers and those 
Table 3. Demography of respondents in the study of the knowledge and practices of dried crayfish sellers in Samaru, Sabo and Kaduna central market

\begin{tabular}{|c|c|c|c|c|c|}
\hline Variables & Categories & Samaru & Sabo & Central market & Total \\
\hline \multirow{4}{*}{ Age (years) } & $<20$ & $3(15 \%)$ & $3(10 \%)$ & $1(2 \%)$ & 7 (7%) \\
\hline & $20-39$ & $12(60 \%)$ & $12(40 \%)$ & $28(56 \%)$ & $52(52 \%)$ \\
\hline & $40-59$ & $4(20 \%)$ & $15(50 \%)$ & $18(36 \%)$ & $37(37 \%)$ \\
\hline & $\geq 60$ & $1(5 \%)$ & $0(0 \%)$ & $3(6 \%)$ & $4(4 \%)$ \\
\hline \multirow{2}{*}{ Gender } & Male & $4(20 \%)$ & $10(33 \%)$ & $22(44 \%)$ & $36(36 \%)$ \\
\hline & Female & $16(80 \%)$ & $20(67 \%)$ & $28(56 \%)$ & $64(64 \%)$ \\
\hline \multirow{5}{*}{$\begin{array}{l}\text { Duration of Selling } \\
\text { (years) }\end{array}$} & $<1$ & $2(10 \%)$ & $2(6.67 \%)$ & $4(8 \%)$ & $8(8 \%)$ \\
\hline & $1-5$ & $7(35 \%)$ & $1(3.33 \%)$ & $9(18 \%)$ & 17 (17 \%) \\
\hline & $6-7$ & $7(35 \%)$ & $12(40 \%)$ & $31(62 \%)$ & $50(50 \%)$ \\
\hline & $11-15$ & $2(10 \%)$ & 15 (50\%) & $6(12 \%)$ & $23(23 \%)$ \\
\hline & $>16$ & $2(10 \%)$ & $0(0 \%)$ & $0(0 \%)$ & $2(2 \%)$ \\
\hline \multirow{2}{*}{$\begin{array}{l}\text { Eating of } \\
\text { uncooked crayfish }\end{array}$} & Yes & $13(65 \%)$ & $30(100 \%)$ & $28(56 \%)$ & $71(71 \%)$ \\
\hline & No & $7(35 \%)$ & $0(0 \%)$ & $22(44 \%)$ & $29(29 \%)$ \\
\hline \multirow{2}{*}{ Tasting dried crayfish } & Yes & $9(45 \%)$ & $10(33 \%)$ & $19(38 \%)$ & $38(38 \%)$ \\
\hline & No & $11(55 \%)$ & $20(67 \%)$ & $31(62 \%)$ & $62(62 \%)$ \\
\hline \multirow{3}{*}{$\begin{array}{l}\text { Source of buying } \\
\text { the crayfish }\end{array}$} & Source (Fishermen) & $1(5 \%)$ & $6(20 \%)$ & $16(32 \%)$ & $23(23 \%)$ \\
\hline & Wholesaler & $13(65 \%)$ & $24(80 \%)$ & $29(58 \%)$ & $66(66 \%)$ \\
\hline & Retailer & $6(30 \%)$ & $0(0 \%)$ & $5(10 \%)$ & 11 (11 \%) \\
\hline \multirow{4}{*}{ Packaging } & Source (Fishermen) & $3(15 \%)$ & $3(10 \%)$ & $4(8 \%)$ & $10(10 \%)$ \\
\hline & Wholesaler & $5(25 \%)$ & $15(50 \%)$ & $22(44 \%)$ & $42(42 \%)$ \\
\hline & Retailer & $2(10 \%)$ & $12(40 \%)$ & $4(8 \%)$ & $18(18 \%)$ \\
\hline & Self & $10(50 \%)$ & $0(0 \%)$ & 20 (40\%) & $30(30 \%)$ \\
\hline \multirow{3}{*}{ Measuring } & Bare hands & $6(30 \%)$ & $8(27 \%)$ & $30(60 \%)$ & $44(44 \%)$ \\
\hline & Measuring cup & $13(65 \%)$ & $21(70 \%)$ & $7(14 \%)$ & $41(41 \%)$ \\
\hline & $\begin{array}{l}\text { Hand covered } \\
\text { with polythene bag }\end{array}$ & $1(5 \%)$ & $1(3 \%)$ & $13(26 \%)$ & 15 (15 \%) \\
\hline \multirow{5}{*}{$\begin{array}{l}\text { Symptoms associated with } \\
\text { consumption of } \\
\text { uncooked dried crayfish }\end{array}$} & Vomiting & $2(10 \%)$ & 1 (3 \%) & $1(2 \%)$ & $4(4 \%)$ \\
\hline & Diarrhoea & $0(0 \%)$ & $0(0 \%)$ & $0(0 \%)$ & $0(0 \%)$ \\
\hline & Fever & $0(0 \%)$ & $0(0 \%)$ & $0(0 \%)$ & $0(0 \%)$ \\
\hline & Stomach ache & $0(0 \%)$ & $0(0 \%)$ & $0(0 \%)$ & $0(0 \%)$ \\
\hline & None & $18(90 \%)$ & 29 (97\%) & $49(98 \%)$ & 96 (96\%) \\
\hline
\end{tabular}


Table 4. Multi-linear regression of the knowledge and practices

of crayfish sellers in Samaru, Sabo and Kaduna central market

\begin{tabular}{|c|c|c|c|c|c|}
\hline \multirow[t]{2}{*}{ Model } & \multicolumn{2}{|c|}{$\begin{array}{l}\text { Unstandardized } \\
\text { coefficients }\end{array}$} & \multirow{2}{*}{$\begin{array}{c}\begin{array}{c}\text { Standardized } \\
\text { coefficients }\end{array} \\
\text { Beta }\end{array}$} & \multirow[t]{2}{*}{$\mathbf{T}$} & \multirow[t]{2}{*}{ Significance } \\
\hline & Beta & Std. Error & & & \\
\hline (Constant) & 1.614 & 0.148 & & 10.912 & 0.000 \\
\hline Processing of dried crayfish & 0.026 & 0.027 & 0.097 & 0.959 & 0.340 \\
\hline Eating of uncooked dried crayfish & 0.001 & 0.023 & 0.003 & 0.029 & 0.977 \\
\hline Tasting dried crayfish before buying & 0.039 & 0.021 & 0.188 & 1.822 & 0.072 \\
\hline Source of buying the crayfish & -0.045 & 0.020 & -0.256 & -2.189 & 0.031 \\
\hline Packaging of the dried crayfish & 0.004 & 0.010 & 0.041 & 0.387 & 0.699 \\
\hline Supplies of dried crayfish & -0.037 & 0.027 & -0.162 & -1.367 & 0.175 \\
\hline Storage of dried crayfish & -0.017 & 0.020 & -0.086 & -0.869 & 0.387 \\
\hline $\begin{array}{l}\text { Measuring and package of } \\
\text { dried crayfish }\end{array}$ & 0.016 & 0.015 & 0.114 & 1.083 & 0.282 \\
\hline Other uses of dried crayfish & 0.166 & 0.039 & 0.408 & 4.219 & 0.000 \\
\hline $\begin{array}{l}\text { Consumption of uncooked } \\
\text { dried crayfish }\end{array}$ & 0.010 & 0.014 & 0.072 & 0.728 & 0.469 \\
\hline
\end{tabular}

Beta-Regression coefficient; T-Test statistic

selling dried crayfish who are in very close proximity as observed during sampling in Sabo; enhancing contamination through the transfer of parasite eggs as they perch from one point to another. A z z a et al. [3] reported a lower prevalence of $6 \%$ for $C$. parvum oocysts on crayfish in Egypt. Also, A b r a ha m et al. [1] described the distribution of parasitic infections in crayfish from 4 sampling zones of Great Kwa river, Cross river State, Nigeria, to have a prevalence of $6.0 \%, 8.7 \%, 15.3 \%$ and $10.0 \%$. The higher prevalence observed in our study could be due to the difference in points of sampling of the product thus, sampling for this study was done at the point of sale; which have undergone some level of unhygienic handling, while other studies sampling was mostly at the point of harvest.

From this study, respondents indicated sourcing the dried crayfish mostly from the wholesalers where this product was displayed in large quantities in an open field and sometimes on bare ground which creates a greater chance of being contaminated with helminth ova and Cryptosporidium oocysts.
The responses from the questionnaires depicted that, there were: poor handling of dried crayfish with unclean hands, eating of uncooked dried crayfish, tasting of dried crayfish, poor packaging, storage, measuring of the dried crayfish, thereby serving as the major contributing factors of helminthosis and cryptosporidiosis. Sometime the products were packaged in unclean bags such as cement paper bags and old newspapers. It should be noted that the crayfish were mostly used and tasted in their dried form as such, which served as the dominant factor for helminth infection and cryptosporidiosis. The concept of eating raw food stuffs is becoming common in our society more or less everywhere these days and crayfish is not an exception. This study has shown that eating of undercooked or raw crayfish could be a possible risk factor to parasitic infections. This was also affirmed by R o th s child [19] who reported that six residents of Missouri and Illinois came down with a rare parasitic disease; paragonimiasis caused by Paragonimus trematodes, or lung flukes, following consumption of uncooked crayfish, between September 2009 and September 2010. 


\section{CONCLUSIONS}

This study has established the occurrence of Cryptosporidium oocysts and helminth ova in dried crayfish sampled from Sabo, Samaru and Kaduna central market. This study has also revealed that there is poor handling and packaging of crayfish at the markets thus, there should be public awareness of the possibility of contamination of dried crayfish by zoonotic organisms detrimental to public health if eaten uncooked. Proper hygiene should be ensured when packaging dried crayfish and there should be proper storage of dried crayfish to avoid contamination by persons, environment, insects or other animals.

\section{ACKNOWLEDGEMENTS}

We sincerely appreciate the efforts of the laboratory staff of the Department of Veterinary Public Health and Preventive Medicine, Faculty of Veterinary Medicine, Ahmadu Bello University, Zaria who assisted in processing the samples.

\section{REFERENCES}

1. Abraham, J. T., Oloko, G. O., Ikpeme, E. M., 2013: Parasites of crayfish (P. clarkia) and lobsters (Macrobrachium vollenhovenic) as indicators of metallic pollution in Great Kwa river, Nigeria. Global J. Agric. Sci., 14, 27-36. DOI: 10.4314/gjas. v14i1.4.

2. Arora, D. R., Arora, B., 2006: Medical Parasitology. 10th edn., B. S. Publishers, New Delhi, India, 166 pp.

3. Azza, M. R., Amro, M., Mohamed, E. M., Abd El-Maksoud, S. A., 2003: Further studies on the role of crayfish (Procambarus clarki) in transmission of some zoonotic parasites in East Delta. In The 3rd International Science Conference, Faculty of Veterinary Medicine, Mansoura University, Egypt, 151-168.

4. Checkley, W., White, C., Jaganath, D., Arrowood, M. J., Chalmers, R. M., Chen, X. M., et al., 2014: A review of the global burden, novel diagnostics, therapeutics and vaccine targets for cryptosporidiosis. The Lancet Infect. Dis., 15, 8594. DOI: 10.1016/S1473-3099(14)70772-8.

5. Cheesbrough, M., 2009: District Laboratory Practices in Tropical Countries, Part 1, 2nd edn., Cambridge University Press, New York, USA, 206-207.

6. Chen, X. M., Keithly, J. S., Paya, C. V., LaRusso, N. F., 2002:
Cryptosporidiosis. N. Engl. J. Med., 346, 22, 1723-1731. DOI: 10.1056/NEJMra013170.

7. Edgerton, B. F., 2002: Hazard analysis of exotic pathogens of potential threat to European freshwater crayfish. Bull. Fr. Pêche Piscic., 367, 813-820. DOI: 10.1051/kmae:2002069.

8. Goldstein, S. T., Juranek, D. D., Ravenholt, O., Hightower, A. W., Martin, D. G., Mesnik, J. L., et al., 1996: Cryptosporidiosis: An outbreak associated with drinking water despite state-of-the-art water treatment. Ann. Intern. Med., 124, 5, 459-468. DOI: 10.7326/0003-4819-124-5-199603010-00001.

9. Jerlyn, K., Sponseller, A., Jeffrey, K., Griffiths, B., Saul, T., 2014: The evolution of respiratory cryptosporidiosis: Evidence for transmission by inhalation. Clin. Microbiol. Rev., 27, 3, 575-586. DOI: 10.1128/CMR.00115-13.

10. Jones, J. B., Lawrence, C. S., 2001: Diseases of yabbies (Cherax albidus) in western Australia. Aquaculture, 194, 221-232. DOI: $10.1016 /$ S0044-8486(00)00508-1.

11. Jourdan, P. M., Lamberton, P. H., Fenwick, A., Addiss, D. G., 2018: Soil-transmitted helminth infections. Lancet, 391, 10117, 252-265. DOI: 10.1016/S0140-6736(17)31930-X.

12. Kumolu-Johnson, C. A., Aledetodun, N. F., Ndimole, P. E., 2010: The effect of smoking on nutritional qualities and shelllife of Clarias gariepinus. Afr. J. Biotechnol., 9, 1, 073-076. DOI: $10.5897 / \mathrm{AJB} 09.548$.

13. Larry, W. B. Jr., Robert, P. R., 1990: Crawfish production: harvesting, marketing and economics. Southern Regional Aquaculture Center. Publication No. 242. Aquaculture Curriculum Guide, 95-114.

14. Moravec, F., 2007: Some aspects of the taxonomy and biology of adult spirurine nematodes parasitic in fishes: a review. Folia Parasitol., 54, 239-257. DOI: 10.14411/fp.2007.033.

15. Nagy, R., Fusaro, A., Conard, W., 2016: "Procambarus clarkii”. Nonindigenous Aquatic Species Database, Gainesville, FL. USGS. Retrieved from Wikipedia on June 14, 2017.

16. Needon, C., Petermann, J., Scheffel, P., Scheibe, B., 1971: Plants and animals (Pflanzen und Tiere). Leipzig, Urania Verlag. In Conference paper 2D Animation Design of Freshwater Lobster Cultivation, KnE Social Sciences. DOI: 10. 18502/kss.v4i12.

17. Putignani, L., Menichella, D., 2010: Global distribution, public health and clinical impact of the protozoan pathogen Cryptosporidium. Interdiscip. Perspect. Infect. Dis., 4, 753512. DOI: $10.1155 / 2010 / 753512$

18. Robert, R., 2010: Disease threats from crayfish, frogs described at IDSA. Center for Infectious Disease Research and Policy (CIDRAP) News. Oct 22, 2010. https://www.cidrap. 
umn.edu/news-perspective/2010/10/disease-threats-crayfish-frogs-described-idsa.

19. Rothschild, M., 2010: Don't eat raw crayfish. Food Safety News. Breaking news for everyone's consumption. December 17, 2010. https://www.foodsafetynews.com/2010/12/raw-crayfishcause-rare-parasitic-disease.

20. Savioli, L., Smith, H., Thompson, R. C. A., 2006: Giardia and Cryptosporidium join the "Neglected Diseases Initiative". Trends Parasitol., 22, 203-208. DOI: 10.1016/j.pt.2006. 02.015 .
21. Taylor, M. A., Coop, R. L., Wall, R. L., 2015: Veterinary Parasitology, 4th edn., Wiley-Blackwell, Ho boken, NJ, 1032 pp.

22. Urquhart, G. M., Armour, J., Duncan, J. L., Dunn, A. M., Jennings, F. W., 2003: Veterinary Parasitology, 2nd edn., University of Glasgow, Scotland, $307 \mathrm{pp}$.

23. Xiao, L., 2010: Molecular epidemiology of cryptosporidiosis: an update. Exp. Parasitol., 124, 80-89. DOI: 10.1016/j. exppara.2009.03.018.

Received September 21, 2020

Accepted December 16, 2020 